This item was submitted to Loughborough's Research Repository by the author.

Items in Figshare are protected by copyright, with all rights reserved, unless otherwise indicated.

\title{
Microhardness and wear behaviour of polycrystalline diamond after warm laser shock processing with and without coating
}

\section{PLEASE CITE THE PUBLISHED VERSION}

https://doi.org/10.1016/j.ijrmhm.2019.04.014

\section{PUBLISHER}

(C) Elsevier

VERSION

AM (Accepted Manuscript)

\section{PUBLISHER STATEMENT}

This paper was accepted for publication in the journal International Journal of Refractory Metals and Hard Materials and the definitive published version is available at https://doi.org/10.1016/j.ijrmhm.2019.04.014.

\section{LICENCE}

CC BY-NC-ND 4.0

\section{REPOSITORY RECORD}

Pacella, Manuela, Marah G. St. John, Nader Dolatabadi, and Amir Badiee. 2019. "Microhardness and Wear Behaviour of Polycrystalline Diamond After Warm Laser Shock Processing with and Without Coating". figshare. https://hdl.handle.net/2134/37666. 


\title{
Microhardness and wear behaviour of polycrystalline diamond after warm laser shock processing with and without coating
}

Manuela Pacella ${ }^{a}{ }^{*}$, Marah Grace Jasmine St. John ${ }^{a}$, Nader Dolatabadi ${ }^{a}$, Amir Badiee ${ }^{b}$

${ }^{a}$ Wolfson School of Mechanical, Electrical and Manufacturing Engineering, Loughborough

University, Loughborough, Leicestershire, LE11 3TU, UK

${ }^{b}$ School of Engineering, College of Science, University of Lincoln, Lincolnshire, LN6 7TS, UK

* Corresponding author: M.Pacella@lboro.ac.uk

ORCID: 0000-0002-5775-1038

Loughborough University, Epinal Way, Loughborough LE11 3TU

\begin{abstract}
Cutting tools made of ultra-hard materials such as polycrystalline diamonds offer superior wear resistance in precision machining of Aluminium alloys. However, the wear properties of these materials are dependent on their microstructural characteristics such as grain size and binder percentage. In this context, the present paper evaluates the effects of two low-energy fibre laser processes (nanosecond pulse duration) on microstructural changes of polycrystalline diamond composites and consequently investigates wear and friction characteristics and micro hardness properties. Pockets were first achieved using a single mode SPI pulsed fibre laser (1064 nm wavelength) inducing both laser shock processing (LSP) and laser peening without coating (LPwC) and characterised using a combination of scanning electron microscopy (SEM), white light interferometry, energy dispersive X-Ray (EDX) and micro hardness analyses. The as-received and processed materials were tested on a pin-on-disc for the evaluation of their wear performance. An analytical model based on the asperities of pin and disc after wear test is proposed to predict the trend of wear performance of different laser-processed materials. LSP with vinyl and quartz at a scanning speed of $500 \mathrm{~mm} \mathrm{~s}^{-1}$ achieved a micro-hardness of $110 \mathrm{GPa}$ at a depth of $632 \mathrm{~nm}$. LPwC at $0.8 \mathrm{GW} \mathrm{cm}^{-2}$ produced hybrid microstructures which share characteristics of laser shock processing and selective laser melted structures. For laser feed speed in the region of $1000 \mathrm{~mm} \mathrm{~s}^{-1}$, micro-indentation tests revealed an improvement of hardness from $70 \mathrm{GPa}$ to $95 \mathrm{GPa}$ at a depth
\end{abstract}


of $670 \mathrm{~nm}$ for LPWC. Tribotest revealed enhanced wear performance for all laser-processed pins and reduced coefficient of friction also validated by increased material removal rate when compared to the as-received material. To the best of authors' knowledge, it is reported for the first time that an improvement of wear performance can be achieved on polycrystalline diamond through LSP and LPWC.

\title{
Keywords
}

\author{
Laser shock peening \\ Laser peening without coating \\ Polycrystalline diamond \\ Microstructural modification \\ Micro hardness \\ Wear properties
}

\section{Introduction}

The use of synthetic polycrystalline diamond (PCD) in construction, subterranean mining and oil and gas drilling applications has increased throughout the years since first invented in 1960s, due to the highly desirable characteristics offered by this material over monocrystalline diamond [1], [2]. PCD consists of several randomly arranged single crystals or grains that are separated by regions called grain boundaries, producing a composite structure with isotropic properties [3]. PCD has outstanding mechanical properties which includes excellent hardness and fracture toughness, high chemical inertness (except with ferrous materials), good abrasion resistance, high thermal conductivity, high Young's Modulus and a low coefficient of friction [4]-[6]. These properties decrease the occurrence of bending, catastrophic failures and chip adherence in tooling applications allowing form accuracy, surface quality and low subsurface damage [4]. When PCD is used as a cutting tool material, it shows tool life improvement up to two orders of magnitude over other industrial standard cutting materials such as tungsten carbide, making it the most suitable cutting tool for precision machining. Despite the advantages of PCD over monocrystalline diamond and other conventional materials used for cutting tools, PCD are exposed to high temperatures and complex wear environments (which are known to cause impact and fretting fatigue) in oil and gas and mining applications, and they can fail due to one or a combination of the following failure modes: smooth wear, gross and micro-chipping, spalling, and gross fracturing. Hence, it is essential that they have exceptional wear/abrasion resistance, impact resistance, fracture toughness and thermal stability [2], [7]. These properties are a result of the microstructural characteristics of PCD materials [2], thus by designing the microstructural characteristics (e.g. diamond grain size and binder volume) it is possible to enhance the performance for a specific application. Previous research [8], [9] reported that cobalt binders in PCD affect PCD structure in condition of thermal and mechanical instability. Since cobalt acts both as a binder and as a catalyst in the synthesis process, during drilling at high temperature conditions, cobalt can promote allotropic conversion of diamond into graphite conveying PCD structures poor thermal stability and abrasive resistance [10]. Furthermore, different thermal expansion coefficients in diamond and cobalt lead to thermal stress and micro-cracking at high temperature, weakening the properties of PDC [11]. Work done by Marron et al. [12] showed that increasing the binder content reduces the toughness of the material even though the binder still adds a toughening effect.

Various processing technologies can be used to modify the microstructure of polycrystalline materials and increase the strength of composites. Conventional laser shock peening (LSP) has been successfully applied to improve fatigue performance of metallic components, particularly in 
the aerospace industry to treat turbine blades, rotors and aerofoils; in the automotive and motor sports industries to treat gear, pistons, crankshafts and connecting rods [13], [14]. In conventional LSP an absorptive layer and a transparent overlay are used to minimise the ablative process and allow the forming plasma to be trapped, expanding under the overlay and creating enough pressure to generate shock waves within the material. This alters the surface microstructure and the state of residual stress which ameliorate the mechanical properties of the target material promoting increased residual compressive stresses, a reduction in frictional properties and wear rate, enhanced surface finish, hardness and fatigue strength [15]. Increase in hardness, yield strength and fatigue strength are results of the formation of dislocations on the laser peened surface which hinder the development of surface-initiated cracks, and therefore prolong the materials' lifespan [16], [17].

Deng and Molian [4] investigated the effect of conventional LSP on PCD materials with $5 \mu \mathrm{m}$ diamond grain size and cobalt binder volume circa $10 \%$. Black paint was used as the absorptive layer and $1 \mathrm{~mm}$ thick fused quartz was applied as transparent overlay. A Q-switched Nd:YAG laser with a wavelength of $1,064 \mathrm{~nm}$ and pulse width of $10 \mathrm{~ns}$ was employed with a defocused beam spot size of approximately $0.6 \mathrm{~mm}$ in diameter on the target sample while the pulse repetition rates utilised were 1,5 and $10 \mathrm{~Hz}$ corresponding to the average power of $0.5,1.8$ and $4.0 \mathrm{~W}$; and energy densities ranged from 4 to $18 \mathrm{GW} \mathrm{cm}^{-2}$. The results showed the formation of phases' inhomogeneity in $\mathrm{PCD}$, densification in the diamond compact, phase transition to various amounts of $s p 3$ and $s p 2$ carbon, increased hardness from $75 \mathrm{GPa}$ to $90 \mathrm{GPa}$ and surface roughness increased with an increase in pulse repetition rate due to the material ablation and crater formation. It was revealed that the resulting inhomogeneous distribution of phases in the composite was due to the localised heating and evaporation of carbon from PCD due to ablation. Laser shock peening without coating (LPwC) was proposed on alumina using an Nd: YAG $1060 \mathrm{~nm}$ laser (pulse repetition rate, $10 \mathrm{~Hz}$; pulse duration, $6 \mathrm{~ns}$; spot diameter, $9.5 \mathrm{~mm}$ ) at pulse energy between $30 \mathrm{~mJ}$ and $966 \mathrm{~mJ}$ [18]. An increase in hardness and an enhancement of fracture toughness by $42 \%$ were reported at $966 \mathrm{~mJ}$. This occurred because of an increase in residual compressive stresses in laser peening, which formed because of dislocation through plastic deformation, allowing better indentation response under mechanical loading. Kulkarni et al. [16] reported that the probability of tensile stresses arising beneath the surface is greater without coating than with the aid of an absorptive layer. They reported that without the ablative layer, temperature increases, and surface ablation occurs. This not only reduces the peening intensity but also promotes negative deformations. This was previously reported by Fabbro et al. [19]: after the shock, the surrounding undeformed matter reacts by generating tensile strains and stresses on the impacted zone. On the other hand, Kalainathan et al. [20] investigated the effect of laser pulse density on surface roughness, surface residual stress, microhardness, and corrosion behaviour of 316L steel specimens processed via LPwC. It was reported that the microhardness of the specimen improved by $30-40 \%$ after $\mathrm{LPWC}$, and that the state of surface stress improved from $12 \mathrm{MPa}$ to a maximum of $-273 \mathrm{MPa}$. The microhardness investigation confirmed that $\mathrm{LPWC}$ resulted in work hardening and the depth profile of hardness showed that the depth of hardened layer increased with increase in laser pulse density. The surface roughness analysis revealed an increased roughness after laser peening suggesting a direct correlation with laser pulse density.

Several studies investigated the change of materials properties post LSP and LPwC on steels and some ceramics, however there is no research conducted on LSP and particularly LPWC applied to $P C D$. The effect of $L P W C$ on wear, friction characteristics and micro hardness properties of PCD has never been investigated before.

In the need of improving PCDs' resistance to impact and shock loading [2] and enhancing PCDs' wear performance in real machining applications, the objectives of the proposed research are twofold. Firstly, two laser processing methods are proposed to improve wear resistance and 
micro-hardness of polycrystalline diamond composites while maintaining finishing tolerances. Secondly, an evaluation of the impact of LSP and LPWC on hardness and wear performance of PCD is investigated via topographical analysis, micro-indentation and wear tests, thus establishing the basis for adopting the proposed technique for PCDs' microstructure design.

\section{Materials and Methods}

\subsection{Materials}

A commercially available $0.5 \mathrm{~mm}$ layer of polycrystalline diamond (PCD) directly synthetized on a tungsten carbide substrate was selected for this study. The PCD used in the experiments is a multimodal grain composite with average diamond grain size of 2-30 $\mu \mathrm{m}$ infiltrated by cobalt as metallic binder (Co binder volume circa 10\%) supplied by Element Six Ltd. Cook and Bossom [21] reported that the selected PCD (multi-modal grain) composite is mostly used when edge strength and edge quality are required, thanks to its good thermal stability in applications and good abrasion resistance.

\subsection{Low-energy laser processing}

A $70 \mathrm{~W}$ Innolas MMS single mode SPI fibre laser (1060 nm wavelength) was used to process the samples. The computer numerically controlled (CNC) laser machine was operated in pulse mode and delivered pulses based on direct modulation of the seed laser allowing programmed waveforms. The waveforms are the results of an optimization of the peak power at a specific pulse repetition rate. At the waveform considered for the experiments the repetition rate for optimised peak power was $70 \mathrm{kHz}$, the pulse duration was $46 \mathrm{~ns}$, and the maximum pulse energy was $1 \mathrm{~mJ}$. Beam diameter at the focal points was measured to be approximately $29 \mu \mathrm{m}$. Two techniques were employed to perform the experiments: laser shock processing without coating (LPWC) at variable energies and LSP with an absorptive/ablative layer combined with a transparent overlay. A black layer made of vinyl was adopted as ablative material (100\% energy absorption [14]) whereas quartz (acoustic impedance $=1.310^{6} \mathrm{~g} / \mathrm{cm}^{2} \mathrm{~s}$ [22]) was selected as transparent overlay. Laser parameters and ranges for the experiments are reported in Table 1 . The experiments without coatings ( $L P w C$ ) involved two values of intensity: $20 \%$ and $50 \%$. LPwC at $20 \%$ intensity is referred in the text as LPWC at low-energy (LE), while LPWC at $50 \%$ intensity is expressed as LPwC at high-energy (HE).

Table 1. Warm laser-shock processing parameter range.

\begin{tabular}{lll}
\hline Process parameters & $\begin{array}{l}\text { Without coating } \\
(\mathrm{LPwC})\end{array}$ & $\begin{array}{l}\text { Vinyl and quartz } \\
(\mathrm{LSP})\end{array}$ \\
\hline Intensity I $(\%)$ & $20-50$ & 70 \\
\hline Repetition frequency $\mathrm{f}(\mathrm{kHz})$ & 35 & 70 \\
\hline Feed speed FS $\left(\mathrm{mm} \mathrm{s}^{-1}\right)$ & 1000 & 500 \\
\hline Track distance TD $(\mu \mathrm{m})$ & 40 & 40 \\
\hline Pocket Size $\left(\mathrm{mm}^{2}\right)$ & 1 & 1 \\
\hline Pulse duration $\tau(\mathrm{ns})$ & 46 & 46 \\
\hline Power density $\left(\mathrm{GW} \mathrm{cm}^{-2}\right)$ & $0.2-0.8$ & 0.8 \\
\hline Focal depth $(\mathrm{mm})$ & $55-58.52$ & 57.37 \\
\hline Distance between spots $(\mu \mathrm{m})$ & 28 & 7 \\
\hline Number of times, $\mathrm{R}$ & 1 & 1 \\
\hline
\end{tabular}




\subsection{Characterisation method}

All test specimens were placed in a methanol-filled glass vial and cleaned in a water-filled ultrasonic bath for 30 minutes after laser processing to remove any debris or deposition due to the tape or ablated particles. A JEOL Zeiss SEM was used to perform imaging and chemical composition using energy dispersive X-ray spectroscopy (EDX). Images were taken at X150 and $\mathrm{x} 1000$ of as-received and laser processed areas. The mapping feature was used to determine any changes in chemical composition due to the different processes. A 3D white light interferometer (Alicona Infinite Focus) was used with a vertical resolution of $110 \mathrm{~nm}$ and lateral resolution of 2.13 $\mu \mathrm{m}$. This allowed the topographical analysis of the laser processed/peened areas before and after testing. Each sample was scanned, and three to five single profiles were extracted from top, bottom and centre of each area. For each sample, three Abbott-Firestone's curves were plotted based on ISO 13565, and their respective 2D roughness parameters Rk, Rpk and Rvk extrapolated from each curve. Their 3D counterparts namely Sk, Spk and Svk were derived based on ISO 25178 from the Abbott-Firestone's curve relative to the entire surface.

Indentation tests were conducted with a NanoTest system (Micro Materials Ltd.) equipped with a Vickers indenter. Three measurements were taken per each sample to increase accuracy: one at the centre of square sample and two at 100 microns distance left and right from the initial measurement. All hardness measurements on PCD were performed at room temperature $\left(23^{\circ} \mathrm{C}\right)$ and controlled load. A holding (dwell) time was set (30 s) to allow negligible creep displacement. A thermal shift correction was used so that absolute values of a thermal drift rate were usually well below $0.05 \mathrm{~nm} \mathrm{~s}^{-1}$. During the indentation test, a maximum load of $500 \mathrm{mN}$ was applied on the asreceived and processed samples. To investigate the hardness variation a rate of $3 \mathrm{mN} \mathrm{s}^{-1}$ was used for loading and $6 \mathrm{mN} \mathrm{s}^{-1}$ for unloading.

\subsection{Tribotest}

Tribotests were performed using a fully instrumented in-house pin on disc tribometer machine under ambient air in dry condition. Four PCD samples were selected for the wear tests: one asreceived, 2 LPWC samples and one LSP with vinyl and quartz. Since the PCD samples were used as upper samples (i.e. pin), areas of $4 \mathrm{~mm}^{2}$ were cut for each of the four conditions using electrodischarge machining (EDM) after laser processing. The PCD samples (pin) were fixed, while a disc made of EN36c steel coated with PVD DLC (ta-C) was rotated. The thickness of the coating was approximately $1.7 \mu \mathrm{m}$. The physical properties of the fixed material (PCD) and the rotating one (DLC ta-C) are presented in Table 2.

Table 2: Physical properties of PCD and DLC coating on EN36c steel [23]-[25].

\begin{tabular}{llllll}
\hline Materials & Density $\left(\mathrm{kg} \mathrm{m}^{-3}\right)$ & $\begin{array}{l}\text { Young's } \\
\text { modulus }(\mathrm{GPa})\end{array}$ & $\begin{array}{l}\text { Thermal conductivity } \\
\left(\mathrm{W}\left(\mathrm{m} \mathrm{K}^{-1}\right)\right.\end{array}$ & $\begin{array}{l}\text { Hardness } \\
(\mathrm{GPa})\end{array}$ & Poisson's ratio \\
\hline PCD & $3300-4000$ & 810 & 700 & $60-65$ & 0.070 \\
\hline DLC & $1900-3000$ & $700-900$ & $1.3-3.5$ & 80 & $0.03-0.23$ \\
\hline
\end{tabular}

The system for tribotest was first calibrated by applying frictional forces at both sides of the load cell (from -30 N to $50 \mathrm{~N}$ ) with a force gauge (FK Sensor Sauter $\mathrm{GmbH}$ ) and the corresponding electric volts of each of the forces were recorded. This information was then used to plot a graph 
of force versus electric volts. After calibration, experiments were conducted at a load of $24 \mathrm{~N}$ and the corresponding mean contact pressure was $6 \mathrm{MPa}$. The applied sliding velocity was $4 \mathrm{~ms}^{-1}$ and a fixed sliding distance of $200 \mathrm{~m}$ was selected for all the experiments. A schematic of the in-house pin on disc tribometer is shown in Figure 1. Wear tests were conducted for each of the processed and as-received samples. Testing only one sample per condition might not be enough to draw statistically valid conclusions; hence, materials' characteristics, variation of surface topography and machine uncertainty were carefully considered as potential sources of error affecting the coefficient of friction. Previous tests [26] conducted using the set-up in Figure 1 recorded a maximum tolerance in coefficient of friction of \pm 0.015 based on materials' variation and machine uncertainty. Furthermore, laser processing is a reliable technique for manufacturing repeatable textures with tolerance in the order of $\pm 20 \mathrm{~nm}$ [11], [27]. Thus, it was assumed that the effect of laser process on the variance of measured friction (using the same laser parameters) would be negligible. Based on these assumptions the predicted variation of coefficient of friction at steady state would be \pm 0.015 . The way the results might be affected by this variation is discussed in Section 3.3.

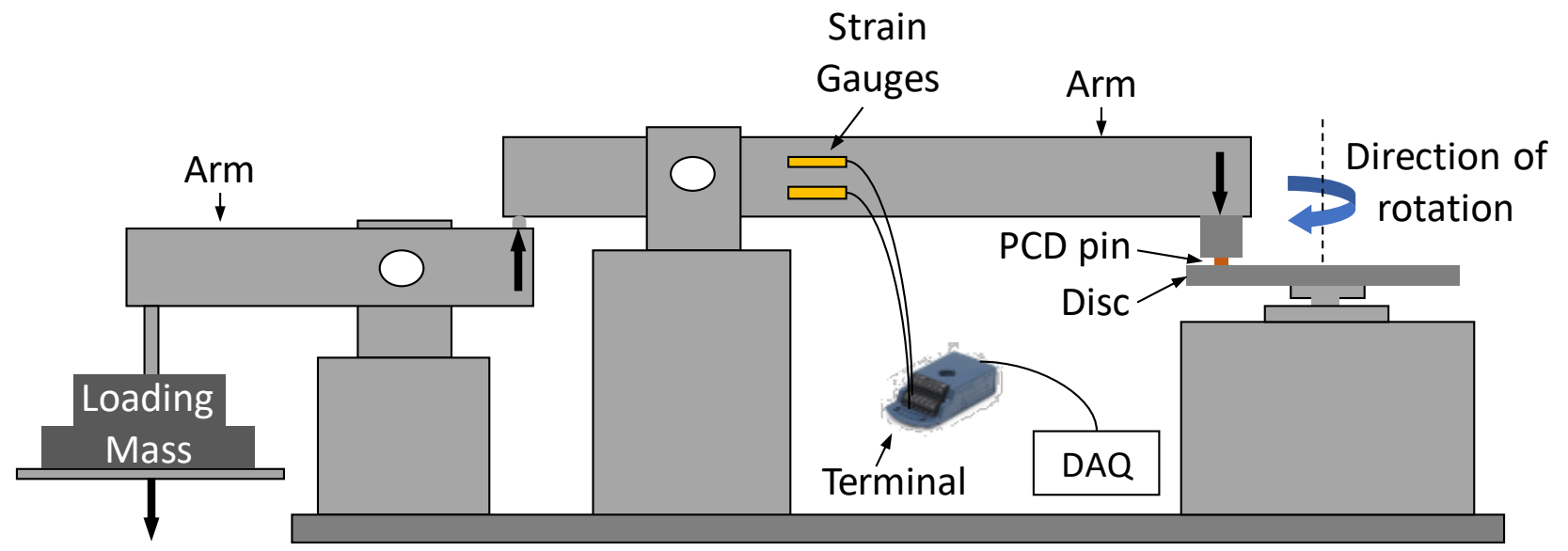

Figure 1: Schematic of pin-on-disc tribometer utilised for friction measurements.

The tested pins were scanned on the Alicona white light interferometer to obtain 3D surface roughness profiles and all the scanned surfaces were post-processed in TalyMap software. Additionally, the wear marks (grooves) left on the rotating disc were analysed using a Bruker NpFlex machine at $x 5$ magnification with a vertical resolution of $0.15 \mathrm{~nm}$. 3D profiles of the worn areas/tracks along with surface profiles were taken. The depth and width of the tracks were also measured to determine the volume of material removed by each of the tested pins (one asreceived and three processed materials).

An analytical model based on the asperities of pin and disc after wear test was developed to predict the trend of wear performance of different processed materials. The different mechanisms of generated friction were therefore considered in order to understand the frictional characteristics of the processed polycrystalline diamond materials. Dry friction comprises of adhesion and deformation due to the surface asperities interaction [28] as expressed in equation (1):

$F=F_{a}+F_{d}$ 
where, $F_{a}$ and $F_{d}$ are adhesion and deformation components of dry friction respectively. Adhesive friction is present during the plastic deformation of asperities and due to asperities' cold welding. Deformation friction is mainly driven by ploughing action. The sharper geometrical and asperity discontinuities are abraded, and grits are pulled into the contact. Ploughing friction is noticeably larger for new surfaces and coefficient of friction reaches a steady state with the surfaces wear. An elastic-plastic asperity contact model is developed to predict the real contact area of the rough surfaces and hence the adhesive friction force. There is insufficient information about the highly transient ploughing mechanism (i.e. dimensional and geometrical properties of grits). Thus, ploughing is not included in the computational model and the predicted coefficients of friction are compared with tribometry results only at their steady state.

At the steady state, probability distribution of asperity heights is assumed to be the exponential function of surface separation, $d^{*}$ (Figure 2 ).

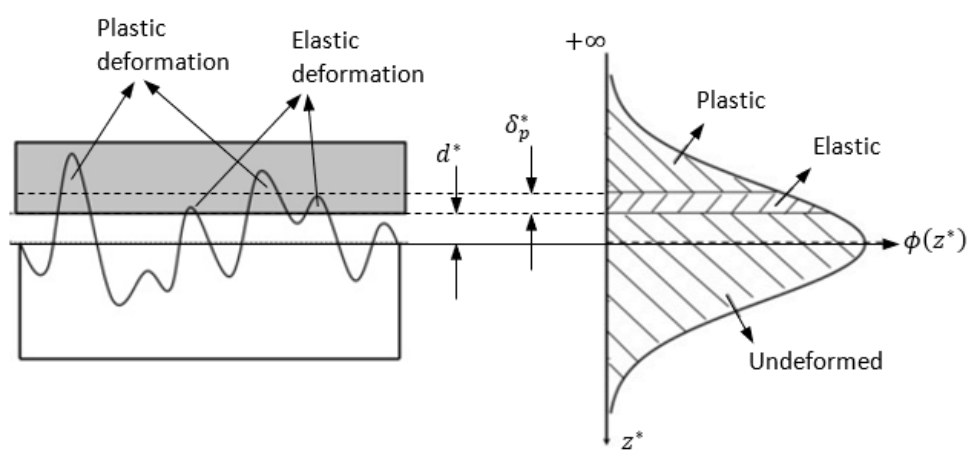

Figure 2: Asperities contact model and the probability distribution representing elastic and plastic deformation regions.

The contacting asperities deform elastically, unless their deformation exceeds the critical interference, $\delta_{p}^{*}$, at the inception of plastic deformation [29] (Figure 2) as expressed in equation (2): $\delta_{p}^{*}=0.76 R\left(H / E^{*}\right)^{2}$

where, $R, H$ and $E^{*}$ are asperity's radius of curvature, hardness of the softer material and composite modulus of elasticity, respectively. Elastic deformation takes place in the separation interval $\left(d^{*}, d^{*}+\delta_{p}^{*}\right)$ and plastic deformation is present in $\left(d^{*}+\delta_{p}^{*}, \infty\right)$. The total contact area, $A_{t}$, and contact load, $W_{t}$, can be predicted encapsulating elastic and plastic deformations [28], as reported respectively in equation (3) and (4).

$A_{t}=\pi R \sigma \eta e^{-d^{*}} \int_{0}^{\delta_{p}^{*}} \delta^{*} e^{-\delta^{*}} \mathrm{~d} \delta^{*}+2 \pi R \sigma \eta \int_{d^{*}+\delta_{p}^{*}}^{\infty} \delta^{*} e^{-\delta^{*}} \mathrm{~d} \delta^{*}$

$W_{t}=\frac{4}{3} R^{1 / 2} \sigma^{3 / 2} E^{*} \eta e^{-d^{*}} \int_{0}^{\delta_{p}^{*}} \delta^{* 3 / 2} e^{-\delta^{*}} \mathrm{~d} \delta^{*}+2 \pi R \sigma H \eta \int_{d^{*}+\delta_{p}^{*}}^{\infty} \delta^{*} e^{-\delta^{*}} \mathrm{~d} \delta^{*}$

where $\sigma$ and $\eta$ are composite asperity height and density of asperity summits in contact area, respectively. $d^{*}$ is nondimensional separation between the two surfaces and $\delta^{*}$ is nondimensional deformation of asperities. Adhesive friction can be evaluated using real contact area $A_{t}$ and the average shear stress at asperity conjunctions, $\tau_{s}[28]$, as reported in equations (5) and (6):

$F_{a}=A_{t} \tau_{s}$

$\tau_{s} \approx 1 / 6 H$

where $H$ is the material hardness and the coefficient of friction $\mu$ is expressed in equation (7): 
$\mu=F_{a} / W_{t}$.

\section{Results and Discussion}

\subsection{SEM, EDX and topographical analysis}

Average surface roughness Ra of the as-received sample based on 3 measurements was $307 \mathrm{~nm}$ and the processed materials showed slightly higher Ra values, namely $310 \mathrm{~nm}, 340 \mathrm{~nm}$ and 350 $\mathrm{nm}$ (Figure 3). 2D parameters Rk and Rpk were $1.02 \mu \mathrm{m}$ and $0.66 \mu \mathrm{m}$ for as-received, $0.9 \mu \mathrm{m}$ and $0.78 \mu \mathrm{m}$ for LPWC HE, $0.87 \mu \mathrm{m}$ and $0.54 \mu \mathrm{m}$ for LPWC LE; $1.37 \mu \mathrm{m}$ and $0.63 \mu \mathrm{m}$ for LSP. 3D surface parameters Sk and Spk were $1.06 \mu \mathrm{m}$ and $1.26 \mu \mathrm{m}$ for as-received, $1.21 \mu \mathrm{m}$ and $1.93 \mu \mathrm{m}$ for LPWC $\mathrm{HE}, 1.09 \mu \mathrm{m}$ and $0.82 \mu \mathrm{m}$ for LPWC LE; $1.22 \mu \mathrm{m}$ and $1.75 \mu \mathrm{m}$ for LSP. Spk (average height of the protruding peaks above the core surface profile) represents the ability of a surface to resist wear, thus, the smaller Spk, the higher the wear resistance.

(a)

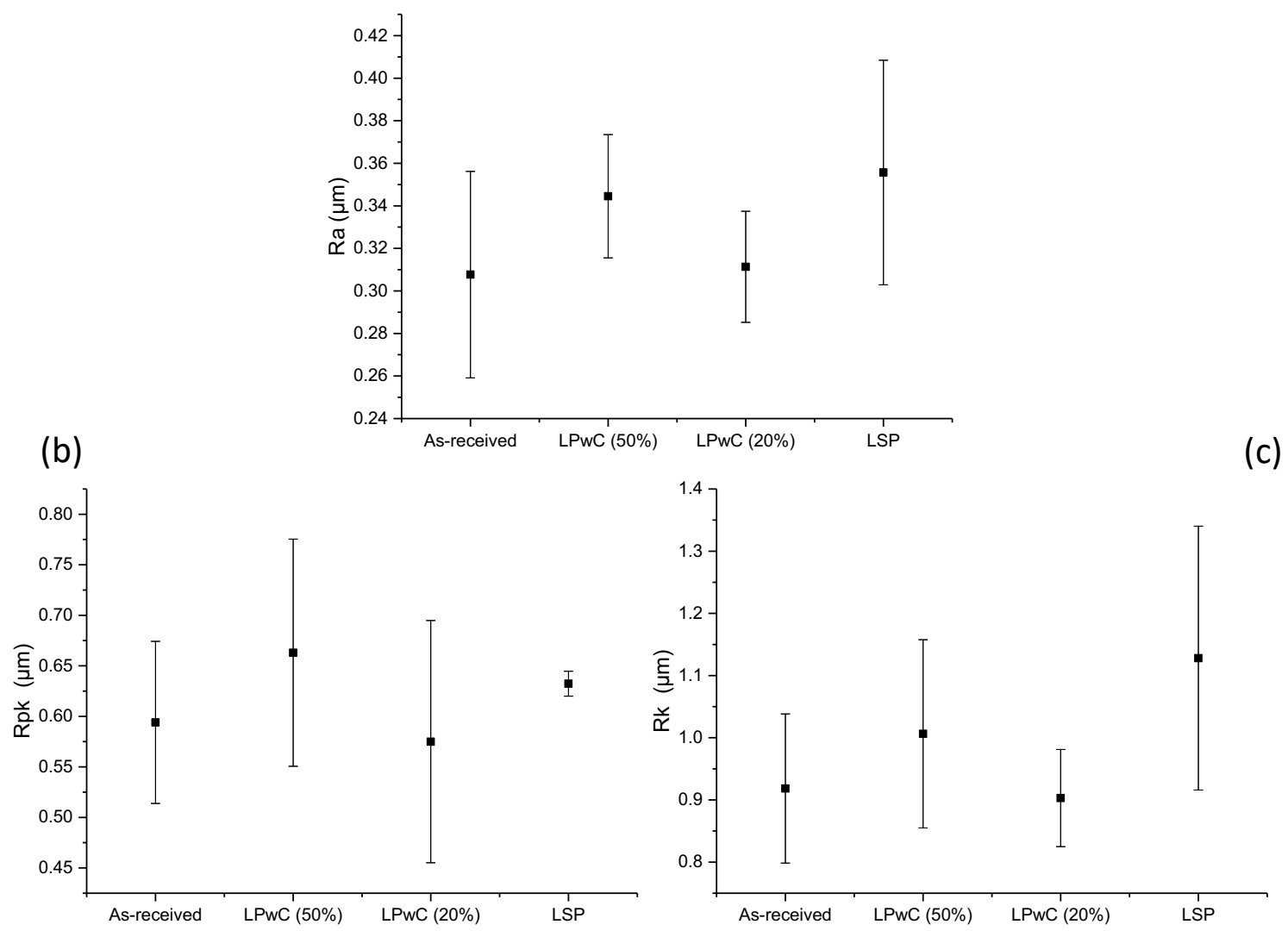

Figure 3: Measurements of 2D roughness parameters extracted from Abbott-Firestone's curves at different processing conditions.

An example of an extracted Abbott-Firestone's for the as-received materials as well as for the processed conditions is shown in Figure $4 \mathrm{a}-\mathrm{d}$. 3D texture measurements showed that LPWC at low energy density (Figure 4c) caused a reduction of Spk from $1.26 \mu \mathrm{m}$ (as-received sample) to 0.827 $\mu \mathrm{m}$. However, the remaining processing conditions caused an increase in Spk to $1.93 \mu \mathrm{m}$ (Figure 4b) and $1.75 \mu \mathrm{m}$ (Figure 4d). This is in agreement with previous research [27] which reported that coarse grain PCD structures have increased binding forces between grains due to the extended intergrowth area. Thus, the laser milling mechanism at low-energy density is purely thermal on the 
binder (cobalt). Melting, ejection, and agglomeration of cobalt at the grain boundaries (Figure 5c) without any conversion of diamond into graphite or amorphous carbon is the expected materials' reaction to LPwC process at low-energy. Deng and Molian [4] studied the effect of laser shock wave treatment (LSP) on a polycrystalline diamond tool (grain size of $10 \mu \mathrm{m}$ and $10 \%$ of cobalt binder volume) in relation to laser induced phase transition and hardness change revealing an increase of surface roughness and the dependence of hardness change from pulse repetition rate due to an increase in dislocation density. The results presented in this paper agree with the increased surface roughness for the LSP process; however, better surface integrity can be retained by using a laser to thermally excite the composite just below its ablation threshold, e.g. through LPwC at low-energy.

(a)
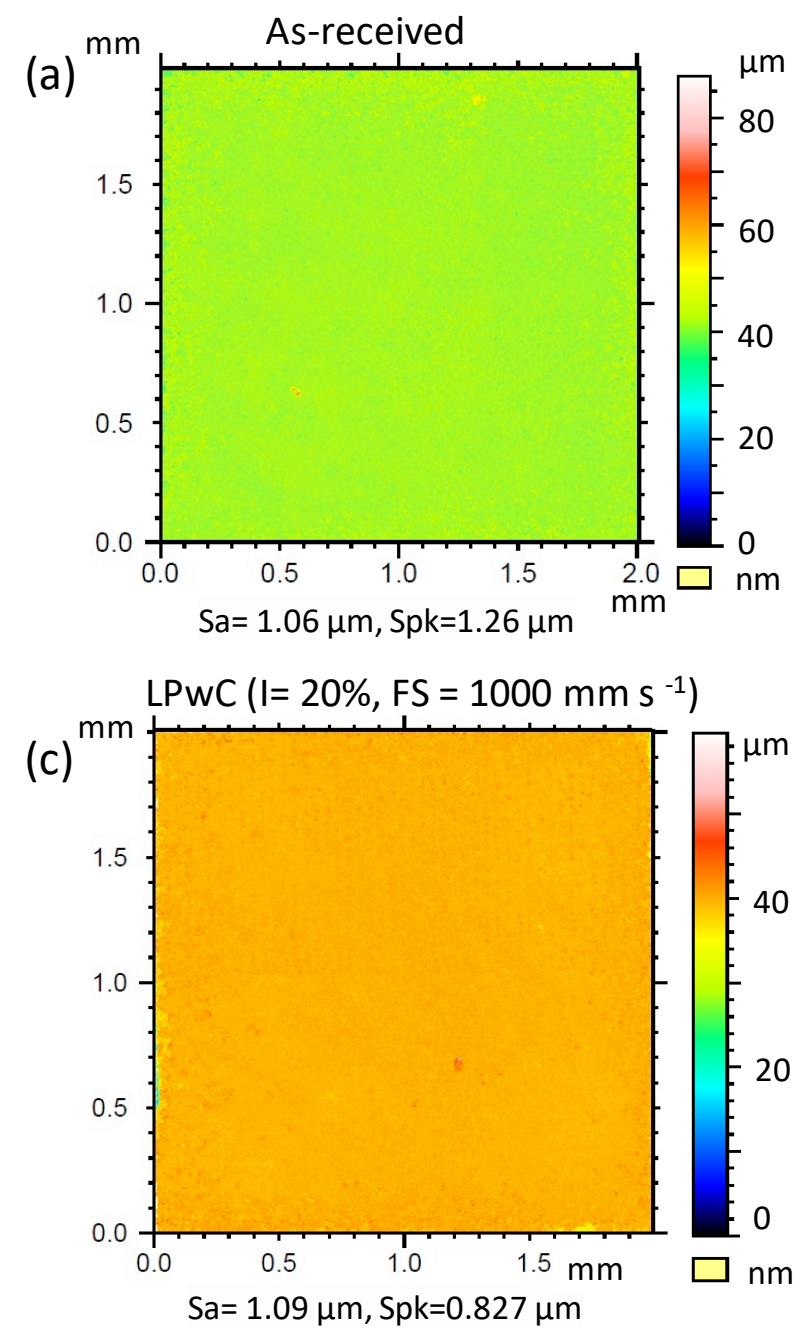
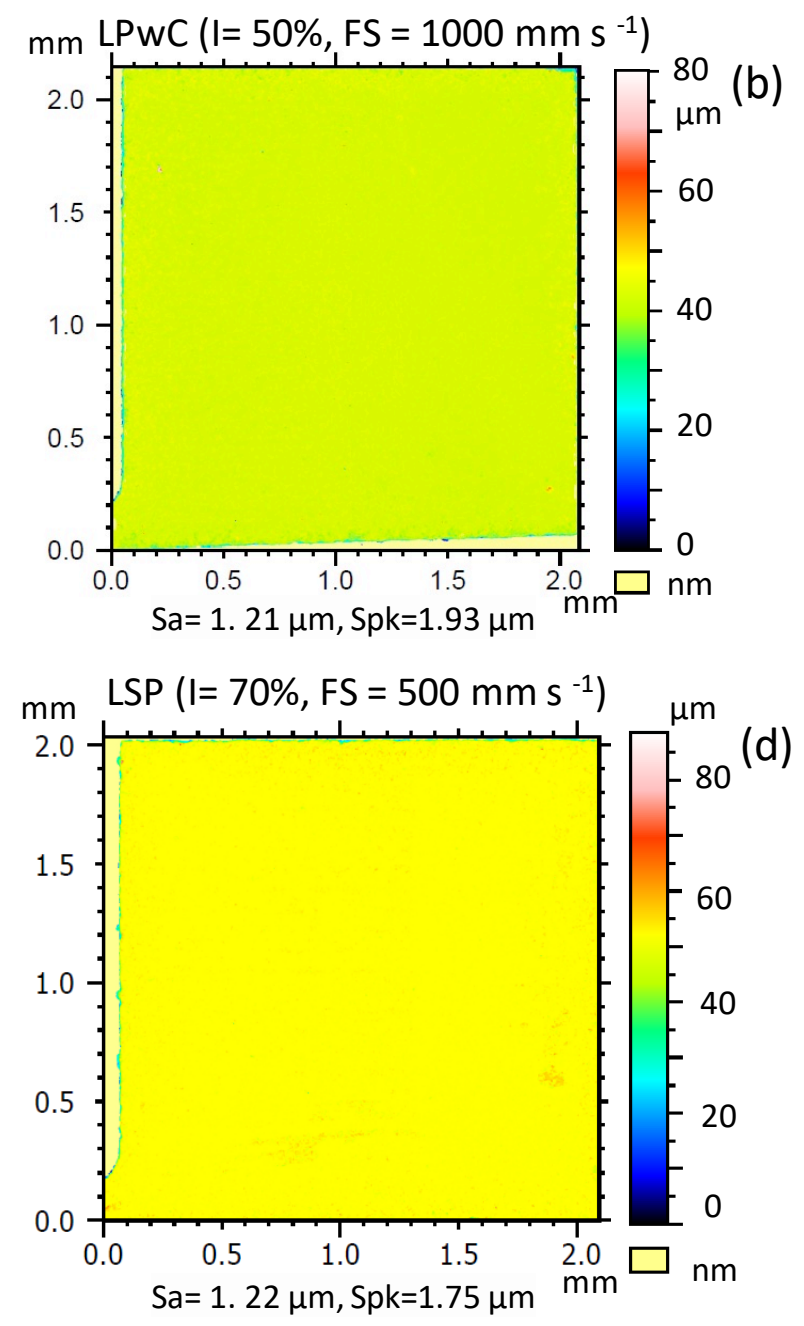

Figure 4: Alicona 3D images and Abbott curve parameter for: as-received material (a) and processed specimens $(b-d)$.

The agglomeration of cobalt at grain boundaries (Figure $5 c$ ) was also confirmed by EDX quantitative analysis (Figure $6 \mathrm{c}$ ) which revealed an increased percentage of binder volume up to $5.8 \%$ compared to $5.3 \%$ in the case of the as-received material (Figure 6a). The agglomeration occurred preferentially at grain boundaries and local defects and it might be due to an early stage oxidation process for diamond grains due to localised increased temperature on $s p 3$ bonded carbon [27], [30]. Processing of PCD at increased energy (Figure 6b) reduced cobalt volume by 
$0.3 \%$, producing a similar thermal etching mechanism as the one induced by LSP (Figure $6 \mathrm{~d}$ ). This is likely to suggest that there is an intensity threshold for the coarse-PCD structure above which the process resembles LSP and below which the process follows a selective laser melting mechanism on cobalt.

(a)
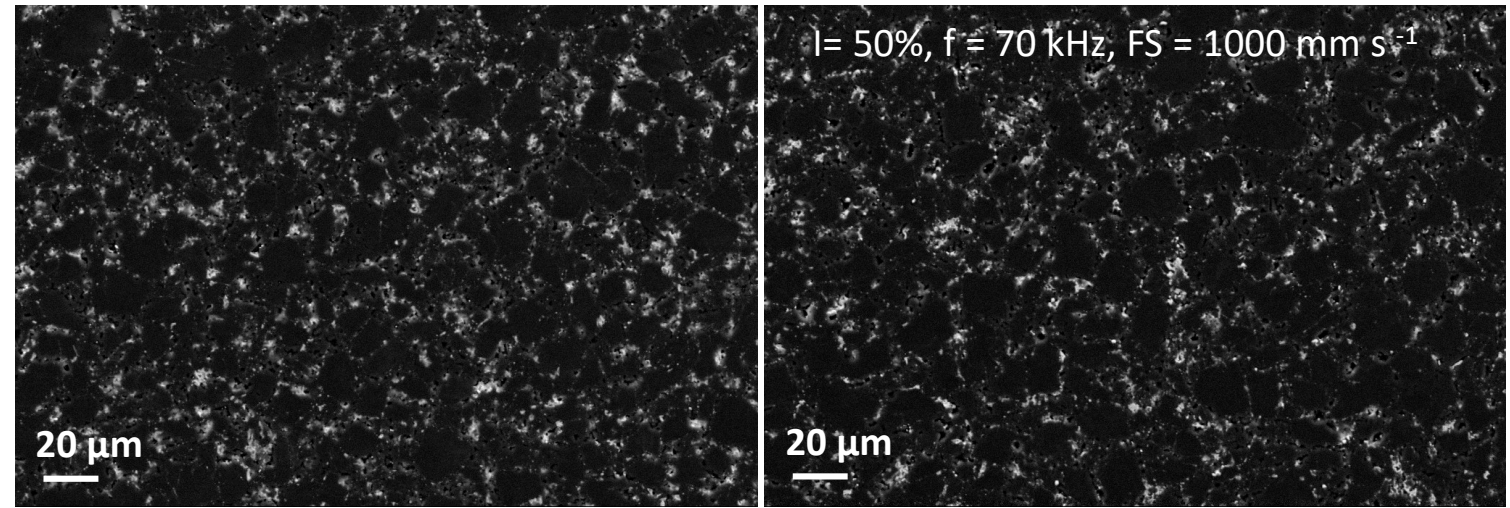

(b)

$$
\text { As-received }
$$

LPWC

(c)

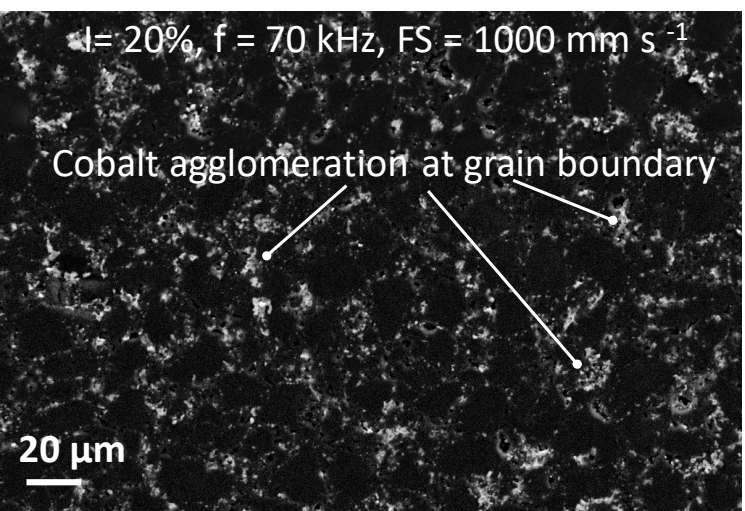

LPWC

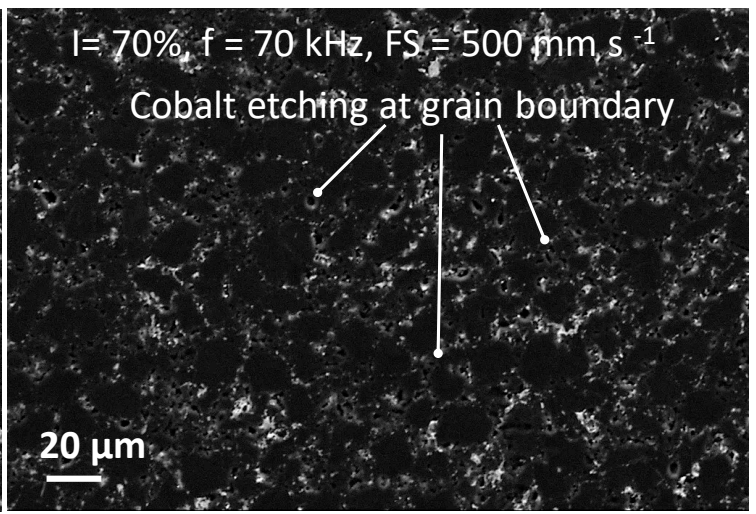

Figure 5: SEM images of PCD microstructure: as-received (a), processed via LPwC at $\tau=46 \mathrm{~ns}, \psi=$ $37.8 \mathrm{~J} \mathrm{~cm}^{-2}, \mathrm{~N}=1(\mathrm{~b}, \mathrm{c})$, processed via LSP with vinyl and quartz (d). 


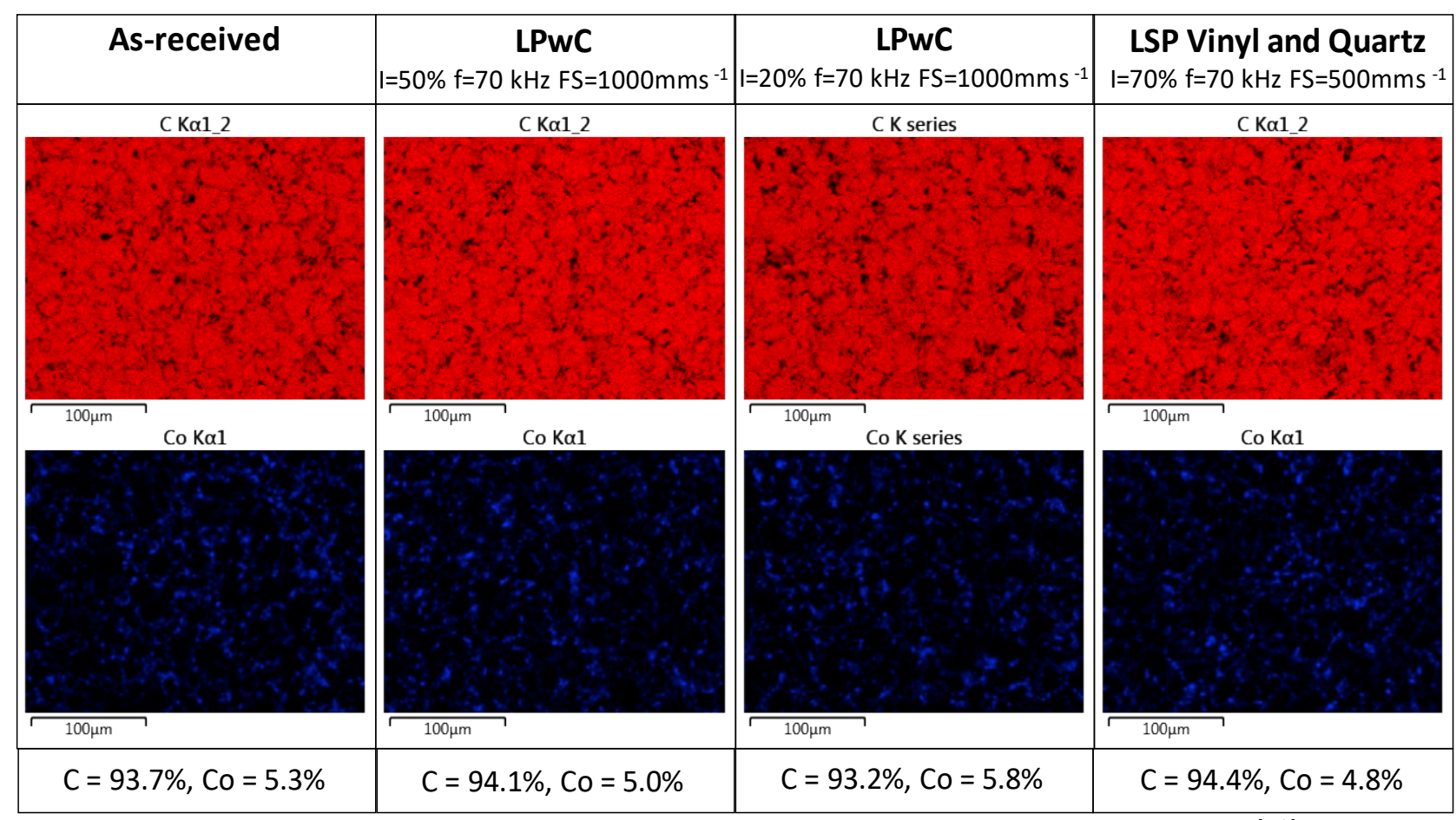

(a)

(b)

(c)

(d)

Figure 6: Energy-dispersive X-ray spectroscopy of the as-received PCD sample (a), two LPwC specimens $(b, c)$ and one LSP sample (d).

\subsection{Micro hardness analysis}

Figure 7 is an indication of the extent of elastic/plastic deformation caused by micro-indentation for each processing condition and for the as-received material. LSP with vinyl and quartz at a scanning speed of $500 \mathrm{~mm} \mathrm{~s}^{-1}$ achieved a micro-hardness of $110 \mathrm{GPa}$ at a depth of $632 \mathrm{~nm}$. Processing of the samples without coating at low energy (LPWC LE) produced more reliable surfaces with hardness in a similar range to the as-received sample (circa $70 \mathrm{GPa}$ ). Increasing the energy by $30 \%$ (LPwC HE) produced an increase in average hardness (95 GPa) and greater variability between minimum and maximum measured values. LPWC at 50\% intensity (LPWC HE) resulted in a hybrid process combining characteristics of LSP and selective laser melted structures. The lowest micro hardness point might be caused by the absence of a sacrificial layer, thus the conversion of energy from pressure to shock could not be made effectively [31]. The standard LSP process involved the use of an ablative layer and transparent overlay, this allowed to achieve a micro hardness of $110 \mathrm{GPa}$. This might be caused by a change in rate of solidification as firstly demonstrated by Hall and Petch in 1951 [32]. The absorbent/ablative vinyl coating prevented melting and ablation, maintaining surface quality. This layer vaporised, forming plasma on the surface with a short duration pulse pressure at power density above $0.8 \mathrm{GW} \mathrm{cm}^{-2}$. The transparent quartz overlay/confining medium was applied to prevent the plasma from expanding away off the surface thereby increasing the intensity of the shock wave [31]. This produced an increased hardness and the highest process reliability, as shown by the scatter variation shown in Figure 7. The dynamic compressive stresses created by the shock waves are highest on the surface and decrease with materials' depth causing plastic deformation to occur when the shock wave stress exceeds the strength (the dynamic yield strength) of the material [14], resulting in high dislocation multiplication and movements which affect the microstructure and properties of the material up to a depth of $630 \mathrm{~nm}$ as shown in Figure 7. 


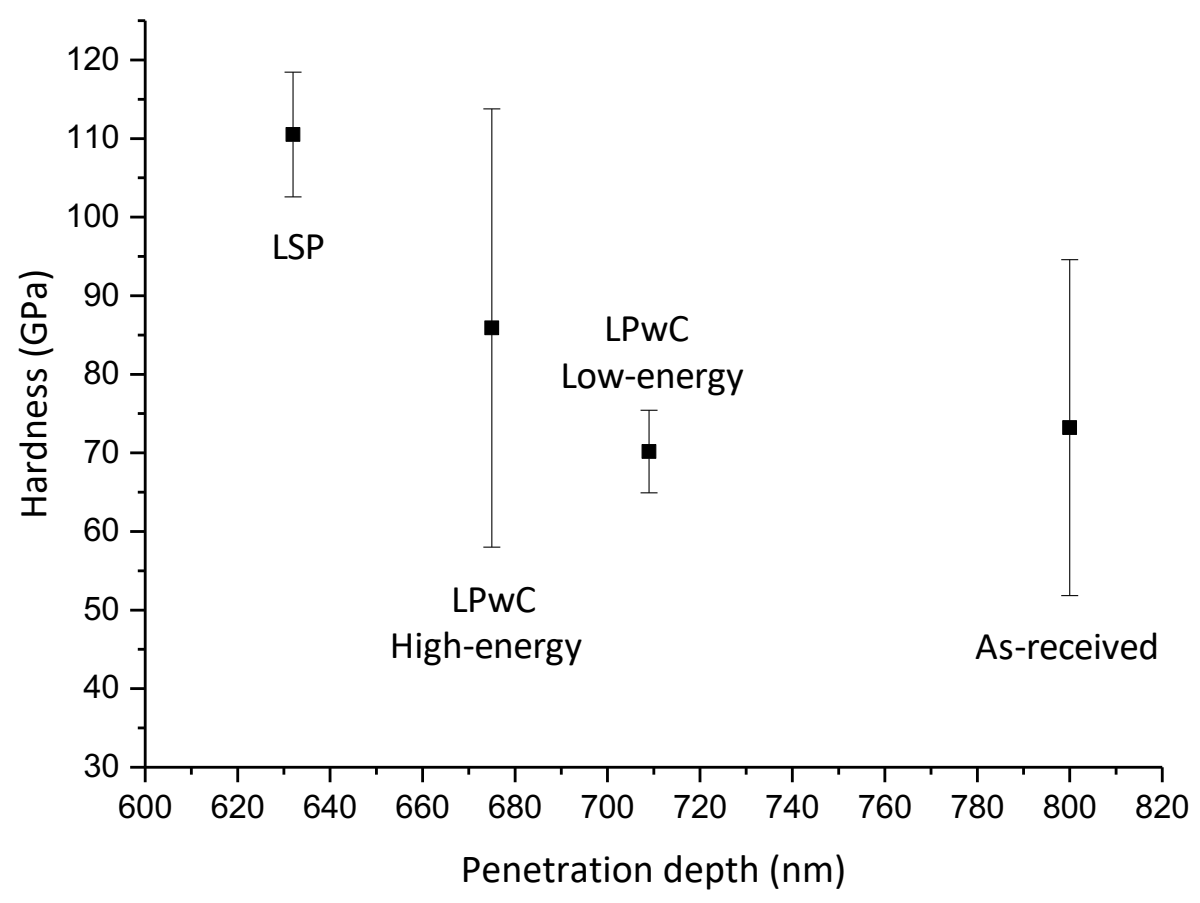

Figure 7: Micro-hardness measurements as a function of the indentation depth at a load of $500 \mathrm{mN}$.

Load versus penetration depth for different processing conditions and for the as-received material at a load below $500 \mathrm{mN}$ is shown in Figure 8. The unloading curves represent the extent of elastic recovery for the different processing conditions. The highest elastic recovery was found in the LSP sample and the LPWC HE (high-energy). These two very different laser processes appear to achieve final surfaces which share common mechanical characteristics. Shortest pulse duration and higher laser irradiances might favour elastic recovery while lower energy densities (Figure 8c) might cause a reduction of elastic recovery in the material promoting plastic deformation. 


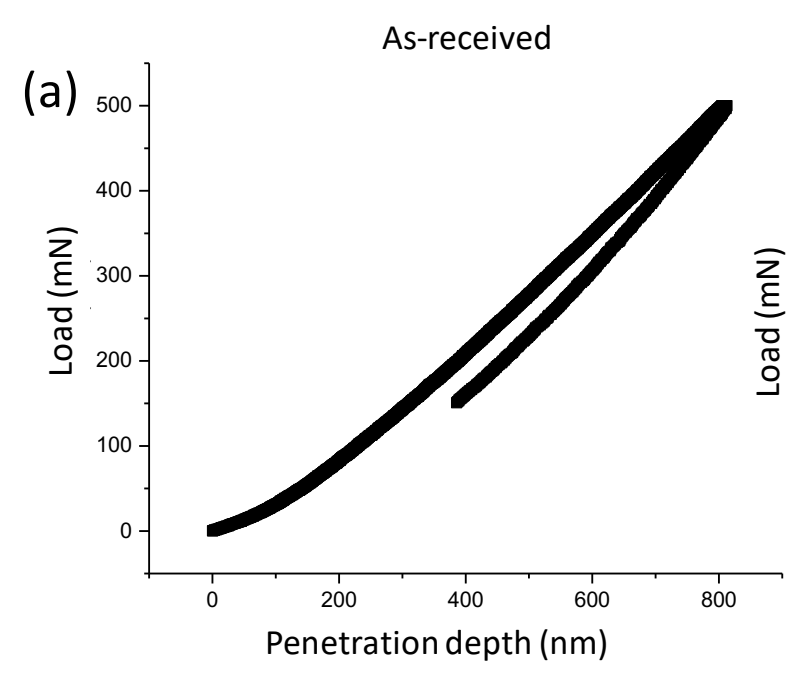

LPWC

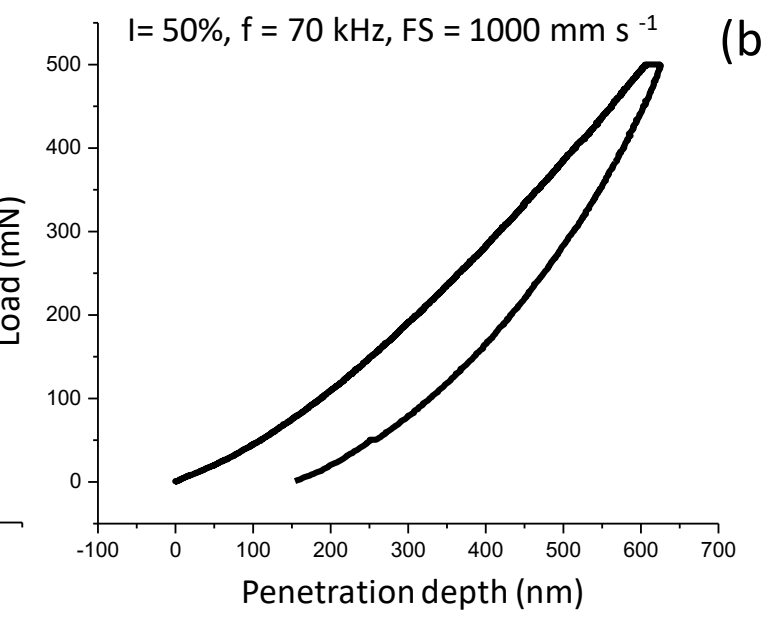

(b)

LPWC

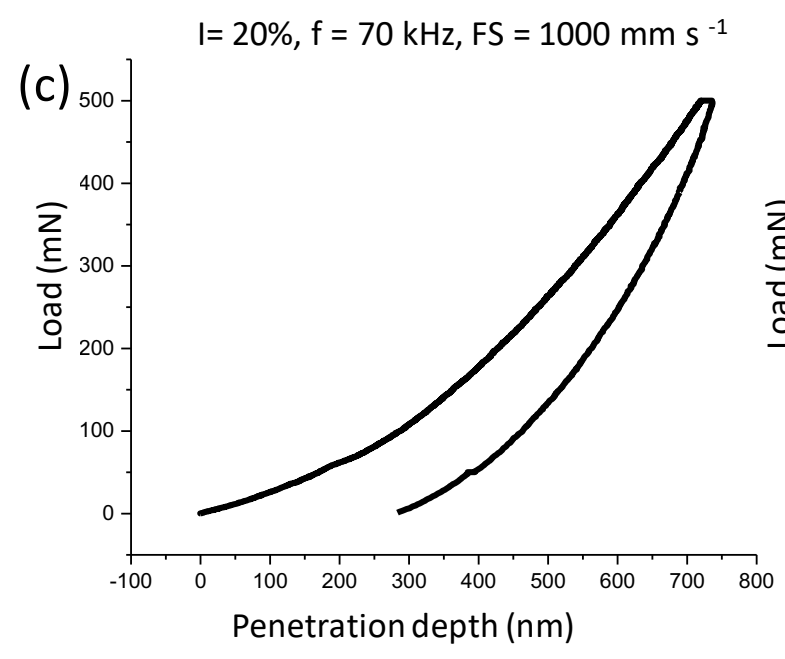

LSP Vinyl and Quartz

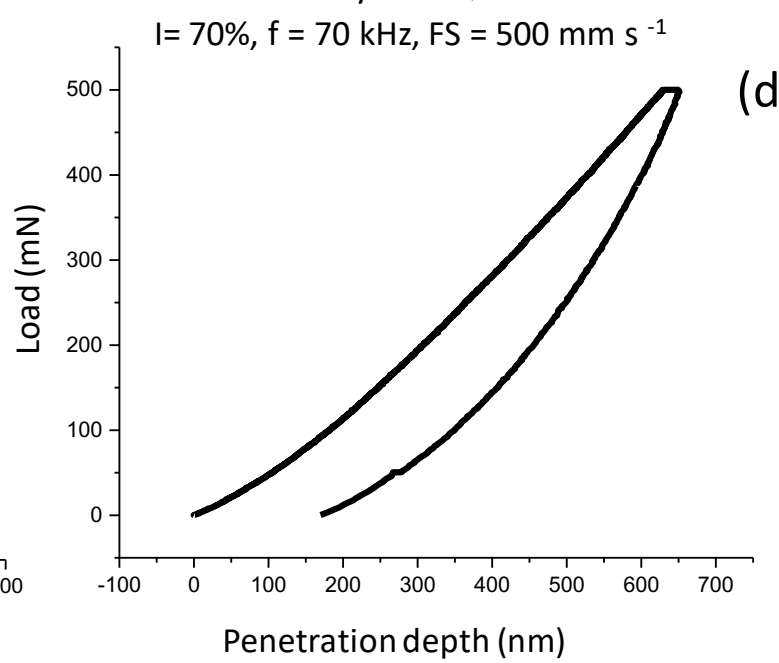

Figure 8: Load versus penetration depth for as-received PCD sample (a), two LPwC specimens (b, c) and one LSP sample (d).

\subsection{Wear performance}

Tribotests demonstrated that the main friction mechanism is through asperity ploughing. This is caused by deformation of the softer counter face asperities by those on the harder counter face surface. It is expected that the coefficient of friction increases with contact pressure, reaching stable values when the surface of the pin is fully in contact with the disc. The coefficient of friction continues to increase as the material ploughs away the asperities of the softer surface, it then stabilises as the exerted pressure is equalised. Wear results for the as-received specimens (Figure 9) showed a gradual increase in the coefficient of friction which is a representation of the transient oscillations, often neglected when determining the coefficient of friction. The tests were performed in dry conditions, and dry friction is less sensitive to sliding velocity for values greater than $0.2 \mathrm{~ms}^{-1}$ (at lower sliding velocities, friction is driven by surface conditions). In dry regime, the main mode of friction is caused by ploughing of asperities in the softer of the contacting surfaces, and the asperities may adhere to the surface. Deformation friction is mainly driven by ploughing action: the sharpest geometrical and asperity discontinuities are abraded, and grits are pulled into contact. Ploughing friction is noticeably larger for new surfaces and coefficient of friction reaches a 
steady state with wearing surfaces (Figure 9). Coefficient of friction of diamond sliding on diamond coatings is comparable with those of diamond on diamond [33]; the coefficient of friction depends on environmental conditions: reported coefficient of friction for diamond at low gas pressure is 0.1 , however the friction increased as high as 0.8 as temperature increased [33]. Plots of the coefficient of friction for the as-received material and the three processed samples highlighted a trend in the material wear behaviour based on the manufacturing process. A clear difference between laser shock processing and laser peening without coating was found. Both LSP and LPwC processed samples (high-energy, HE and low-energy, LE) showed an increase in coefficient of friction (spike in Figure 9) at a sliding distance of circa $2 \mathrm{~m}$ possibly due to an increase in temperature which is of different extent for the three specimens. The different magnitude of the spikes is related to the process (either LSP or LPwC) which caused a change in cobalt binder volume present on the surface of the treated area, as previously shown in Figure $6 \mathrm{~b}$. A high increase in coefficient of friction (as high as 0.6 ) is reported in the graph for LPWC at high-energy $(I=50 \%)$ and EDX analysis on this sample also revealed a decreased percentage of binder present after processing. A reduction of cobalt in the PCD matrix (compared to the as-received material) might have contributed to reduction in the thermal conductivity of the composite, which favoured a localised increase of temperature during asperity ploughing. As a result, accumulation of debris prevented the two surfaces in contact to slide, contributing to an increase of coefficient of friction. This is in accordance with Bowden and Tabor's model for friction [34]: for high wear rates, when wear debris from the disc increases and it ploughs the asperities, these resist the motion at the interface between the two sliding surfaces, causing a high increase of friction. Inversely, for the LPwC at low-energy $(I=20 \%)$, the initial spike in the coefficient of friction is circa 0.27 , and EDX analysis of this sample showed an increased percentage of binder after processing preferentially agglomerated at grain boundaries (Figure $5 \mathrm{c}$ ). The increased cobalt percentage might have resulted in an enhancement of thermal conductivity of the composite, promoting a rapid conduction of heat during asperity ploughing. Another important factor which might have affected the coefficient of friction is Spk which is defined as average height of the protruding peaks above the core surface profile and it represents the ability of a surface to resist wear. The extent of peak values for the coefficient of friction at different conditions seems to be in line with the measured Spk values (reported in Figure 3): lowest Spk $(0.82 \mu \mathrm{m})$ correspond to lowest increase of friction coefficient as in LPwC LE (Figure 9); highest Spk $(1.93 \mu \mathrm{m})$ correspond to a very high friction (0.6) as in LPWC HE (Figure 9). This wear behavioural model is only verified for the laser-processed conditions, since the as-received specimens seem to follow a standard curve for the coefficient of friction (blue dash line in Figure 9). Coefficient of friction was predicted at steady state utilising the surface parameters for the worn samples reported in Table 3. Thus, these predictions are projected at $200 \mathrm{~m}$ (sliding distance) for comparison with the measured coefficients at steady state (Figure 9). The modelled values reported in Table 3 agree with the steady state values achieved through tribotest. Tests were conducted once since it was assumed that the maximum error in coefficient of friction measurement would be in the order of \pm 0.015 . If the measured values of friction are assumed to be an average (Figure 9 ) and the assumed tolerance $( \pm 0.015)$ is applied as test uncertainty, two trend of friction values would still be identified. One valid for asreceived and LSP samples, with frictions in the range $0.235-0.265$, and another measured for LPWC $\mathrm{HE}$ and LE, with coefficient of friction in the range 0.185-0.215. 


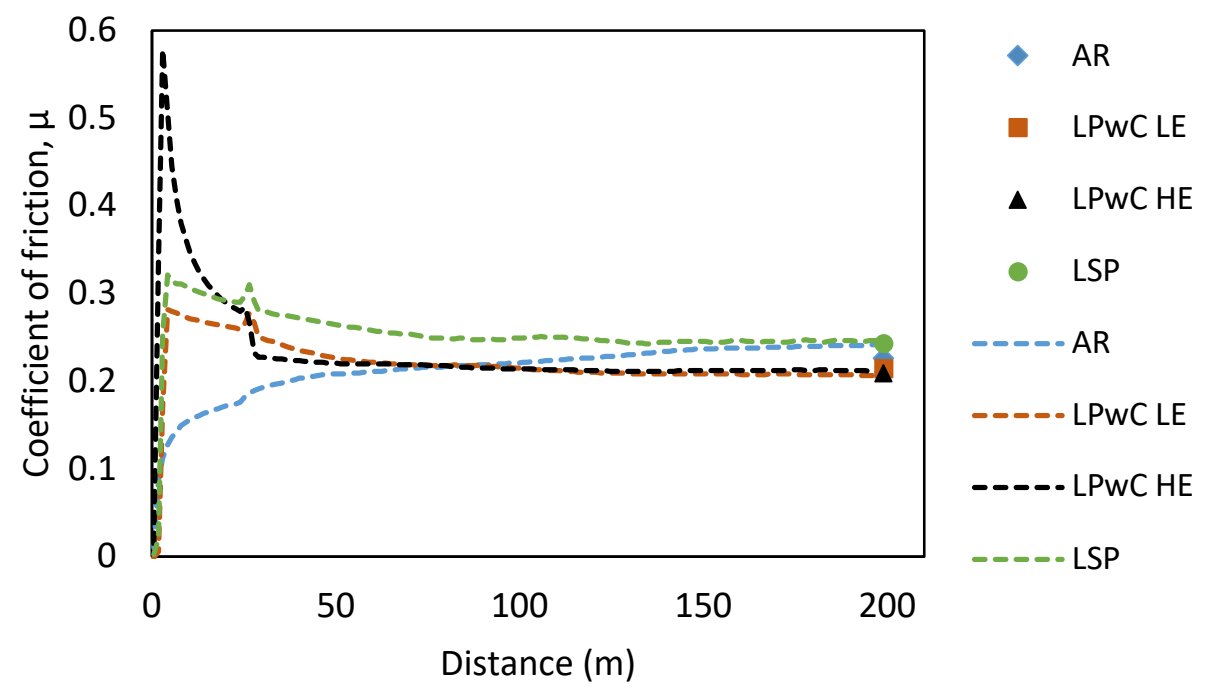

Figure 9: Variation of coefficient of friction with distance: tribometry results (dash lines) and predicted at steady-state condition (marker points) for as-received (AR), LPWC LE (low energy), LPWC HE (high energy) and LSP.

Table 3: Calculated friction coefficient at steady-state condition.

\begin{tabular}{|c|c|c|c|c|}
\hline Material & \multirow{2}{*}{$\begin{array}{c}\text { Coefficient } \\
\text { of friction }\end{array}$} & $\begin{array}{c}\text { Composite } \\
\text { roughness } \boldsymbol{\sigma}\end{array}$ & $\begin{array}{c}\text { Equivalent radius of } \\
\text { asperity } \boldsymbol{R}\end{array}$ & $\begin{array}{c}\text { Asperity Density } \\
\text { per unit area, } \boldsymbol{\eta}\end{array}$ \\
\cline { 3 - 5 } & $\mu \mathrm{m}$ & $\mu \mathrm{m}$ & $\mathrm{mm}^{-2}$ \\
\hline AR & 0.226 & 1.912 & 0.106 & 383 \\
\hline LPWC LE & 0.215 & 1.514 & 0.298 & 362 \\
\hline LPWC HE & 0.209 & 1.940 & 0.167 & 349 \\
\hline LSP & 0.244 & 2.526 & 0.133 & 375 \\
\hline
\end{tabular}

Due to the nature of the test, the main friction mechanism is through asperity ploughing resulting in abrasion on the sliding surfaces, as also confirmed by increased surface roughness of all pins after test (Figure 10). Microscopic analysis of the LPWC LE (Figure 11c and Figure 12c) allowed to identify abrasive wear, also corroborated by an increase of average surface roughness $R$ a at the end of the wear test $(0.4 \mu \mathrm{m})$, as shown in Figure $10 \mathrm{~b}$. Differently processed materials showed various extent of geometrical surface integrity loss: LSP pin showing $160 \mathrm{~nm}$ increase in average Ra, followed by LPwC HE with $100 \mathrm{~nm}$. LPwC LE and as-received pin showed similar results, with only 80 and $90 \mathrm{~nm}$ difference respectively (Figure 10).

Chipping also affected all samples at different extent. After tribotest, edge chipping was found in the order of $300 \mu \mathrm{m}$ (Figure 10a) on the surface of the as-received sample and in the order of 10 $\mu \mathrm{m}$ on the LPwC HE (Figure 10b) and LSP (Figure 10d). 
Before wear test

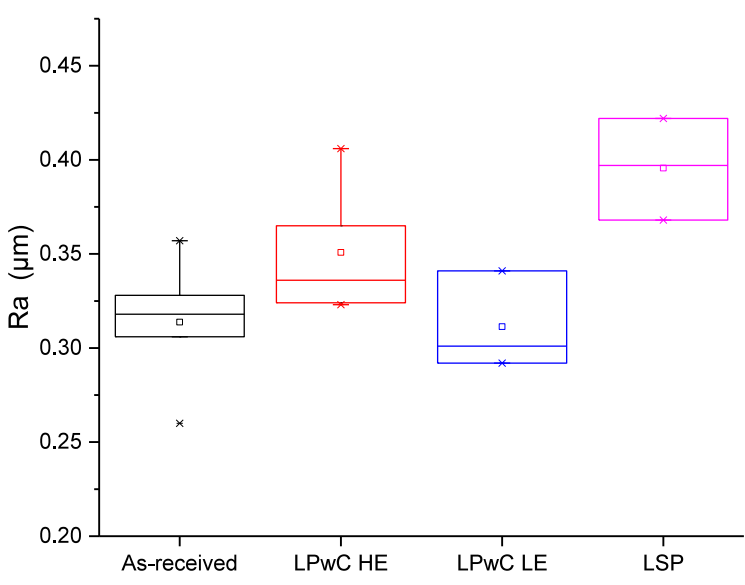

(a)
After wear test



(b)

Figure 10: Boxplot of surface roughness measurements based on ISO 4287 before (a) and after wear tests (b).

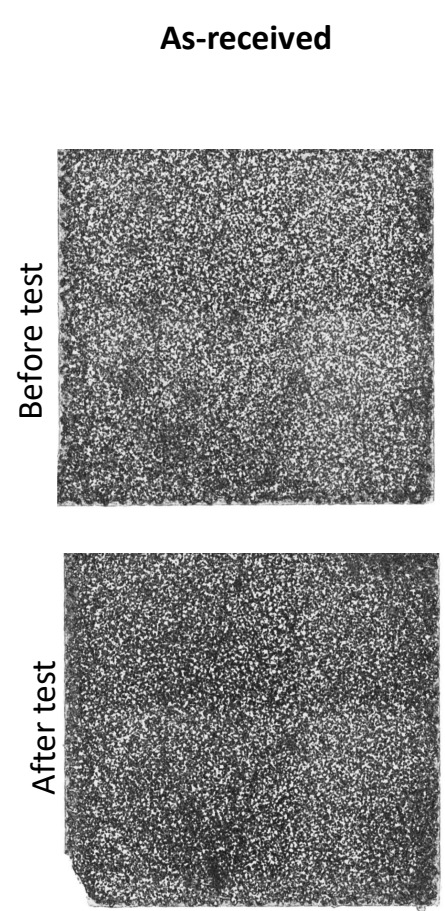

(a)
LPwC

$I=50 \% \mathrm{f}=70 \mathrm{kHz}$

$\mathrm{FS}=1000 \mathrm{mms}^{-1}$
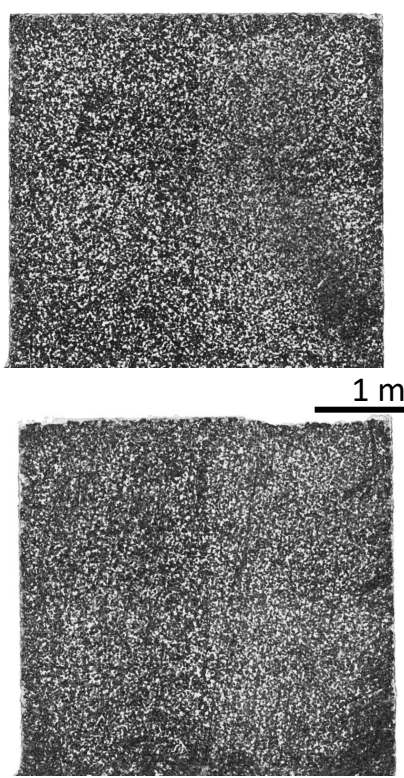

(b)
LPwC

$I=20 \% \mathrm{f}=70 \mathrm{kHz}$

$\mathrm{FS}=1000 \mathrm{mms}^{-1}$
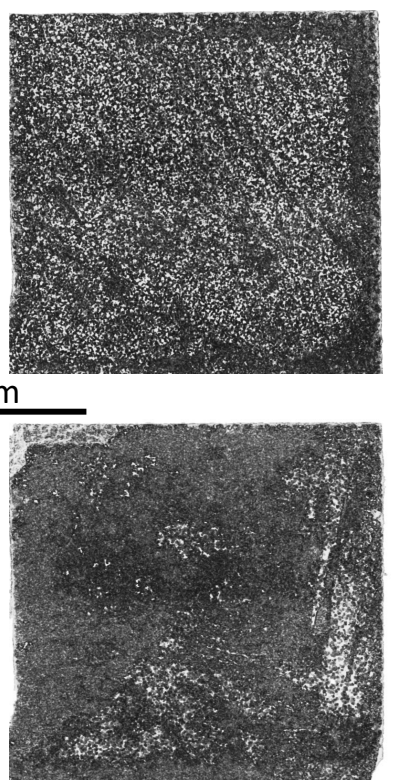

(c)
LSP Vinyl and Quartz

$\mathrm{I}=70 \% \mathrm{f}=70 \mathrm{kHz}$

$\mathrm{FS}=500 \mathrm{mms}^{-1}$
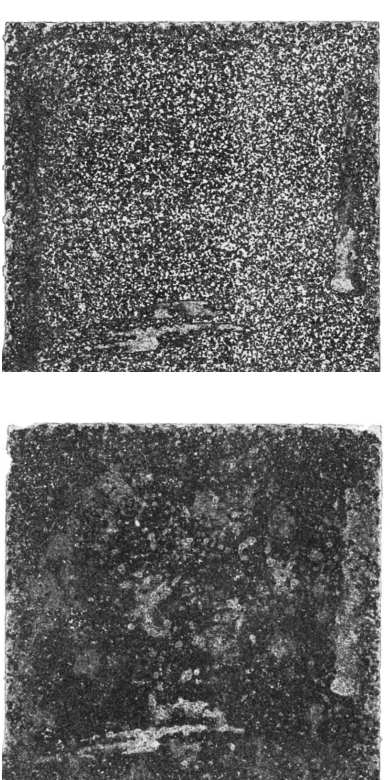

(d)

Figure 11: Optical microscopy images before and after tribotest for: as-received PCD sample (a), two LPwC specimens (b, c) and one LSP sample (d). 
(a)

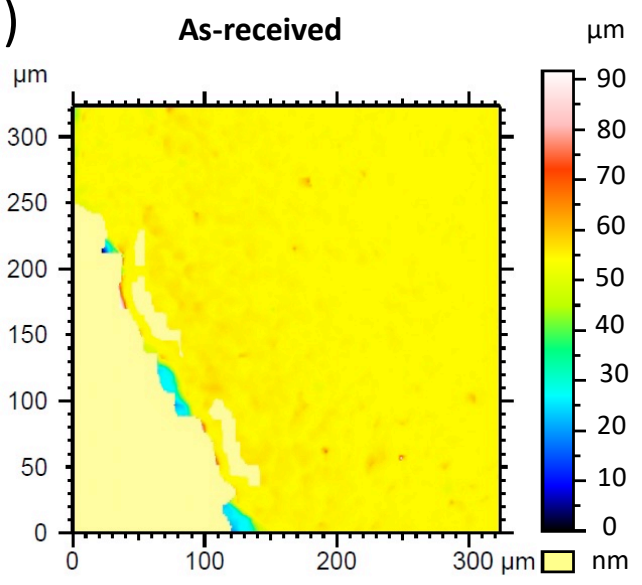

(c)

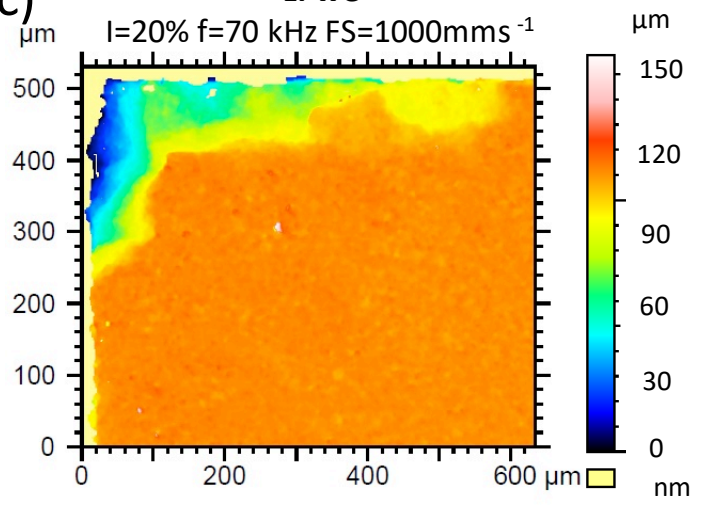

LPwC

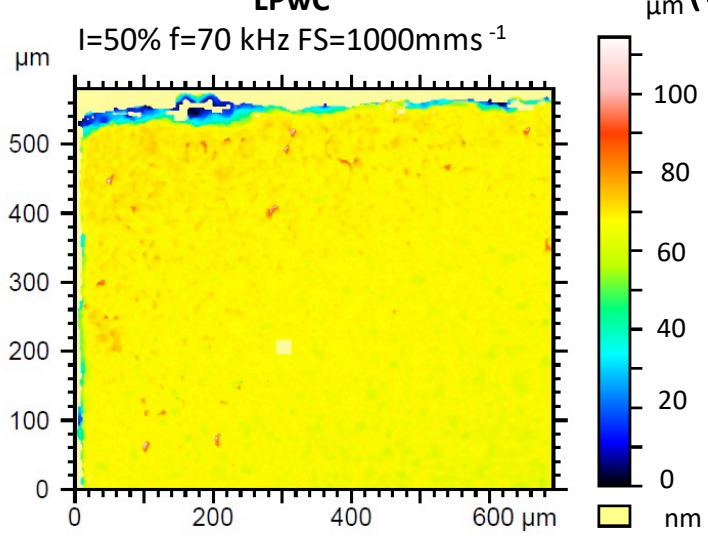

LSP Vinyl and Quartz

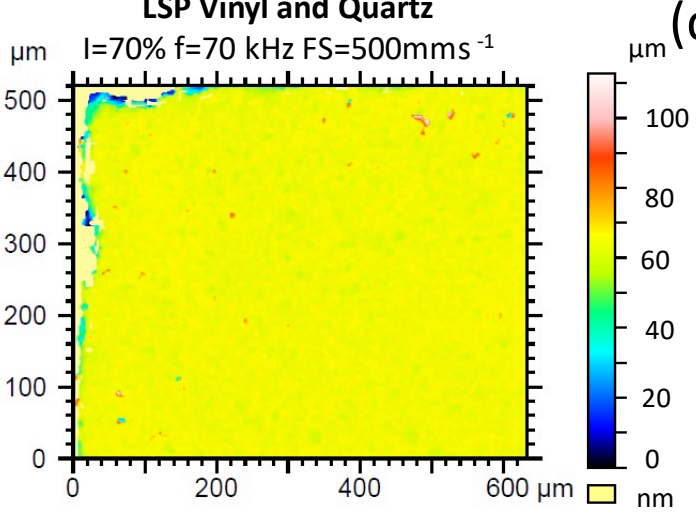

\section{0} .

然

40

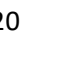

(b)

(n)

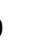

西

Figure 12: White light interferometry of the tested pin: a) as-received PCD sample, b) high-energy LPWC specimen, c) low-energy LPwC specimen, d) LSP sample.

White light interferometry analysis of wear tracks left by each pin on the disc showed that the contact between the two surfaces, pin and disc, does not take place over the entire area (Figure 13). Previous research reported that the real contact area is made of micro-contact points at asperity tips [35]. For this reason, the model used for the prediction of wear performance is based on the asperities of pin and disc after wear test. Analysis of the volume of material removed on the disc by the four pins revealed that all the laser processed samples (LPWC and LSP) improved PCD wear properties regardless of the processing technique (LSP or LPWC) applied. Depths in the order of 1.5-2.5 $\mu \mathrm{m}$ and widths in the order of 250-500 $\mu \mathrm{m}$ were achieved for the laser treated samples (Figure 13b, c and d) while dimensions of the track left by the as-received sample were a maximum of $50 \mathrm{~nm}$ depth and $700 \mu \mathrm{m}$ width (Figure 13a). The cross-sectional areas of tracks left on the disc were approximately measured to be $625 \mu \mathrm{m}^{2}$ for LSP pin, circa $500 \mu \mathrm{m}^{2}$ for LPWC HE, $277 \mu \mathrm{m}^{2}$ for LPWC LE and $22 \mu \mathrm{m}^{2}$ for as-received sample. The corresponding volume of material removed at $200 \mathrm{~m}$ (sliding distance) were: $1.2 \cdot 10^{11} \mu \mathrm{m}^{3}$ for LSP pin, $10^{11} \mu \mathrm{m}^{3}$ for LPWC at $50 \%$ intensity, $5.5 \cdot 10^{10} \mu \mathrm{m}^{3}$ for LPWC at $20 \%$ intensity and $4.4 \cdot 10^{9} \mu \mathrm{m}^{3}$ for as-received sample. Pin produced via LSP showed the highest material removal rate. When used LPWC HE as pin, high wear rates were found. The disc's removal rate is proportional to the coefficient of friction measured during the mechanism of asperity ploughing: an accumulation of debris in the asperities prevented the two surfaces in contact to slide, the asperities resist motion at the interface between the two sliding surfaces, causing a high increase of friction (as high as 0.6 ). 


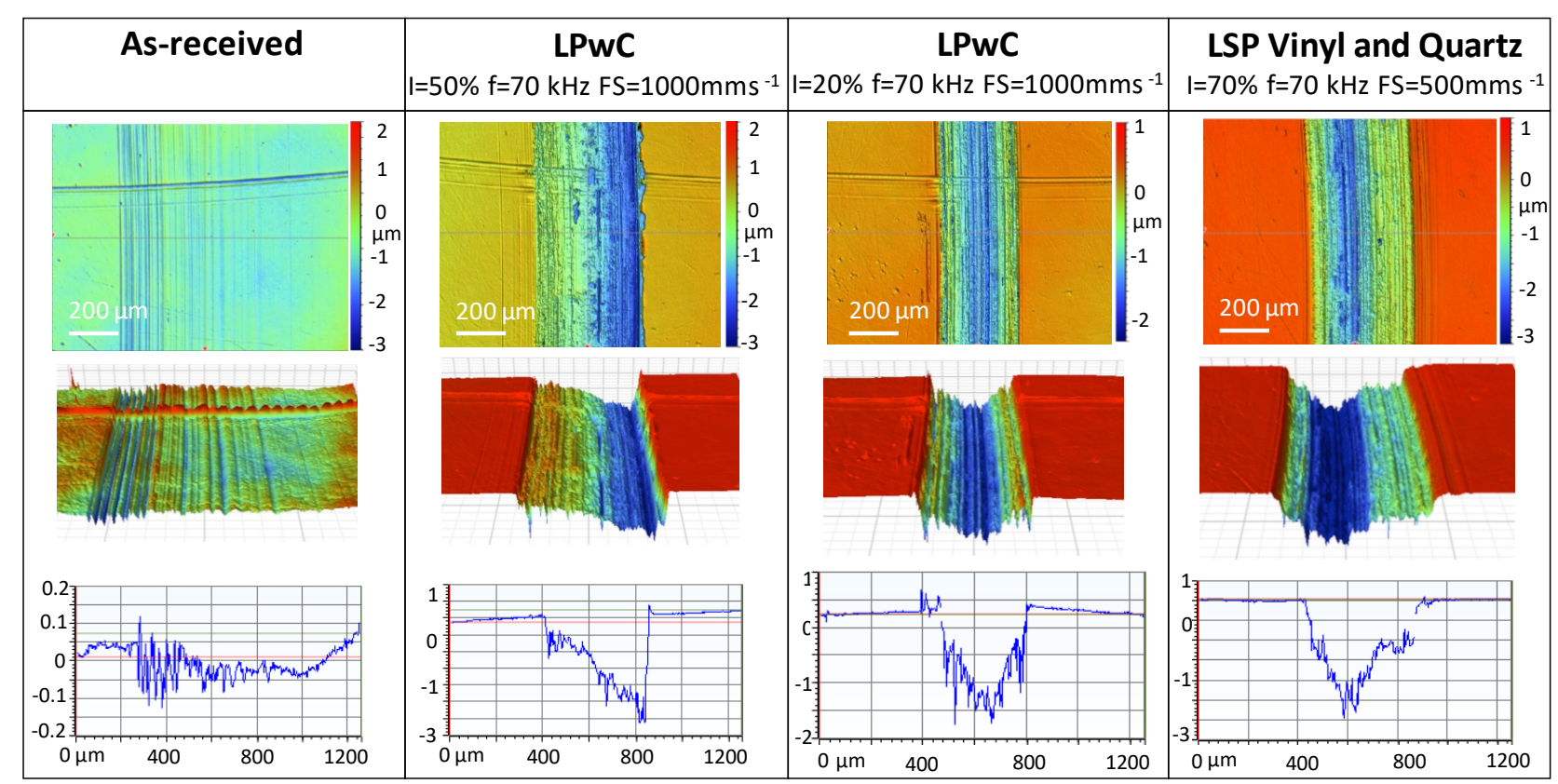

(a)

(b)

(c)

(d)

Figure 13: Wear tracks on the EN36c steel disc produced by a) as-received PCD sample, b) highenergy LPWC specimen, c) low-energy LPwC specimen, d) LSP sample.

\section{Conclusions}

Two laser-based processing technologies were adopted to investigate the viability of fibre lasers for enhancing PCDs' wear performance in real precision machining applications. The effect of LSP and LPWC on hardness and wear performance of PCD was explored via topographical analysis, micro-indentation and wear tests. A step towards the fundamental understanding of the effects of laser-based processing techniques on materials properties (e.g. hardness, micro-structure and metal binder volume) of polycrystalline diamonds was made. SEM/EDX analyses revealed that thermally exciting the PCD structure at low-energy can achieve new microstructures with $0.5 \%$ increased cobalt agglomerated preferentially at grain boundaries and local defects. Processing of PCD at increased energy reduced the cobalt volume by $0.3 \%$, producing a similar thermal etching mechanism as the one induced by laser shock peening. This is likely to suggest that there is an intensity threshold for the coarse-PCD structure above which the process resembles laser shock peening and below which the process follows a selective laser melting (SLM) mechanism on cobalt. LPWC at $0.8 \mathrm{GW} \mathrm{cm}^{-2}$ produced hybrid microstructures which share characteristics of LSP and SLM structures, and, for laser feed speed in the region of $1000 \mathrm{~mm} \mathrm{~s}^{-1}$, micro-indentation tests revealed an improvement of hardness from $70 \mathrm{GPa}$ to $95 \mathrm{GPa}$. Micro-hardness measurements revealed that, LSP with vinyl and quartz at a scanning speed of $500 \mathrm{~mm} \mathrm{~s}^{-1}$ can increase hardness up to $110 \mathrm{GPa}$ due to the strengthening effect provided by the plastic deformation of the crystallites. SEM analyses also confirmed that the increased hardness was accompanied by etching of cobalt. Measurements of the volume of material removed by each of the tested materials demonstrated that all laser processed samples improved wear performance compared to benchmark material. All LPWC samples (both HE and LE) resulted in a reduction of coefficient of friction at steady-state, while coefficient of friction for LSP pin was increased slightly compared to the as-received material. However, pin produced via LSP showed the highest material removal 
rate. When LPWC (high-energy) was used as pin, high wear rates were found during asperity ploughing. This was due to an accumulation of debris in the asperities which prevented the two surfaces in contact to slide, thus the asperities resist motion at the interface between the two sliding surfaces, causing a significant increase of friction.

To the best of authors' knowledge, it is reported for the first time that an improvement of wear performance can be achieved on polycrystalline diamond through LSP and LPWC. The presented findings open new avenues in the utilisation of nanosecond fibre lasers to tailor the wear properties of polycrystalline materials for specific applications.

\section{Acknowledgments}

The authors would like to acknowledge the support of Element Six Ltd. for providing the polycrystalline diamond materials.

\section{Competing interest statement}

I declare that I have no significant competing financial, professional, or personal interests that might have influenced the performance or presentation of the work described in this manuscript.

\section{References}

[1] Holman T, Weber J. Laser shock peening of medical devices. US Patent 2011.

[2] Scott TA. The influence of microstructure on the mechanical properties of polycrystalline diamond: a literature review. Adv Appl Ceram 2018; 117(3):161-176.

[3] Shackelford J. Introduction to Materials Science for Engineers. 8th ed. Pearson; 2015.

[4] Deng C, Molian P. Laser shock wave treatment of polycrystalline diamond tool and nanodiamond powder compact. Int J Adv Manuf Technol 2012; 63(1-4):259-267.

[5] Zhang GF, Zhang B, Deng ZH, Chen JF. An experimental study on laser cutting mechanisms of polycrystalline diamond compacts. CIRP Ann - Manuf Technol 2007; 56(1):201-204.

[6] Wu Q, Wang J, Huang C. Analysis of the machining performance and surface integrity in laser milling of polycrystalline diamonds. Proc Inst Mech Eng Part B J Eng Manuf 2014; 228(6):903-917.

[7] Boland JN, Li XS. Microstructural characterisation and wear behaviour of diamond composite materials. Materials 2010; 3(2):1390-1419.

[8] Liu S, Han L, Zou Y, Zhu P, Liu B. Polycrystalline diamond compact with enhanced thermal stability. J Mater Sci Technol 2017; 33(11):1386-1391.

[9] Pacella M, Axinte DA, Butler-Smith, PW. On the topographical/chemical analysis of polycrystalline diamond pulsed laser ablated surfaces. Proc CIRP 2014; 13:387-392. 
[10] Pacella M, Butler-Smith PW, Axinte DA, Fay MW. FIB/TEM/EELS micro/nanometric investigations of the effects of laser ablation on the diamond/binder structure in polycrystalline diamond composites. J Mater Process Tech 2014; 214(5):1153-1161.

[11] Pacella M, Axinte DA, Butler-Smith PW, Shipway P, Daine M, Wort C. An assessment of the wear characteristics of microcutting arrays produced from polycrystalline diamond and cubic boron nitride composites. J Manu Sci and Eng 2015, 138 (2): 2100101-2100116.

[12] García-Marro F, Mestra A, Kanyanta V, Maweja K, Ozbayraktar S, Llanes L. Contact damage and residual strength in polycrystalline diamond (PCD). Diam Relat Mater 2016; 65:131-136.

[13] Shukla PP, Swanson PT, Page CJ. Laser shock peening and mechanical shot peening processes applicable for the surface treatment of technical grade ceramics: A review. Proc Inst Mech Eng Part B J Eng Manuf 2014; 228(5):639-652.

[14] Ding K, Ye L. Laser Shock Peening: Performance and Process Simulation. 1 st ed. Woodhead Publishing Limited; 2006.

[15] Stafe M, Negutu C, Puscas NN, Popescu IM. Pulsed laser ablation of solids. Rom Rep in Phys 2010; 62(4):758-770.

[16] Kulkarni A, Chettri S, Prabhakaran S, Kalainathan S. Effect of laser shock peening without coating on surface morphology and mechanical properties of Nickel-200. Eng MMSE J 2017.

[17] Shadangi Y, Chattopadhyay K, Rai SB, Singh V. Effect of laser shock peening on microstructure, mechanical properties and corrosion behaviour of interstitial free steel. Surf Coatings Technol 2015; 280:216-224.

[18] Shukla P, Smith GC, Waugh DG, Lawrence J. Development in laser peening of advanced ceramics. Proceedings ILAS 2015; 9657.

[19] Fabbro R, Peyre P, Berthe L, Scherpereel X. Physics and applications of laser-shock processing. J Laser Appl 1998; 10(6):265-279.

[20] Kalainathan S, Sathyajith S, Swaroop S. Effect of laser shot peening without coating on the surface properties and corrosion behavior of 316L steel. Opt Lasers Eng 2012; 50(12):1740-1745.

[21] Cook MW, Bossom PK. Trends and recent developments in the material manufacture and cutting tool application of polycrystalline diamond and polycrystalline cubic boron nitride. Int J Ref Met \& Hard Mat 2000; 18:147-152.

[22] Singh N, Ahuja K, Singh T, Singh S. A Review: Effect of laser peening treatment on properties and life cycle of different materials," IOSR J Mech Civ Eng 2017; 14(1): 83-94.

[23] Shamsa M, Liu WL, Balandin AA, Casiraghi C, Milne WI, Ferrari AC. Thermal conductivity of diamond-like carbon films. Appl Phys Lett 2006; 161921:1-4.

[24] Pastorelli R, Ferrari AC, Beghi MG, Bottani CE, Robertson J. Elastic constants of ultrathin diamond-like carbon films. Diam Relat Mater 2000; 9(3-6):825-830.

[25] Erdemir A, Donnet C. Tribology of diamond-like carbon films: Recent progress and future prospects. J Phys D Appl Phys 2006; 39(18). 
[26] Teo WJ, Dolatabadi N, Rahmani R, Morris N, Rahnejat H. Combined analytical and experimental evaluation of frictional performance of lubricated untextured and partially textured sliders. Lubricants 2018; 6(88).

[27] Gohar R, Rahnejat H. Fundamentals of Tribology, 3rd ed. World Scientific Publishing Europe Ltd.; 2019.

[28] Maugis D. Contact, Adhesion and Rupture of Elastic Solids. Springer series in solid-state sciences; Springer-Verlag berlin Heidelberg; 2010.

[29] Pacella M, Nekouie V, Badiee A. Surface engineering of ultra-hard polycrystalline structures using a nanosecond $\mathrm{Yb}$ fibre laser: effect of process parameters on microstructure, hardness and surface finish. J Mater Process Technol 2019; 266:311-328.

[30] Wang C, Wu Z, Meng D, Lin F, Yue W. Thermal stability of ultrahard polycrystalline diamond composite materials. J Superhard Mater 2015; 37(2):67-72.

[31] Gujba AK, Medraj M. Laser peening process and its impact on materials properties in comparison with shot peening and ultrasonic impact peening. Materials 2014; 7(12):7925-7974.

[32] Hall EO. The deformation and ageing of mild steel: Ill discussion of results. Proc Phys Soc B $1951 ; 64: 747-753$.

[32] Hayward IP. Friction and wear properties of diamonds and diamond coatings. Surf Coatings Technol 1991; 49(1-3):554-559.

[34] Bowden FP, Tabor D. The Friction and Lubrication of Solids. Clarendon Press: London; 1964.

[35] Ramezani M, Ripin ZM. A friction model for dry contacts during metal-forming processes. Int. J Adv Manuf TechnoL 2010; 51(1-4):93-102. 